\title{
TECNOLOGIAS DIGITAIS (TD) APLICADAS NA GESTÃO ESCOLAR PARA PROMOVER A FORMAÇÃO DOCENTE
}

\author{
Digital Technologies (DT) Applied in School Management to Promote Teaching \\ Training
}

\author{
Gilmar Rodrigues Morais ${ }^{1}$ \\ Fernando Barbosa Matos ${ }^{2}$
}

\begin{abstract}
Resumo: Os docentes dos Institutos Federais atuam em diferentes níveis do ensino profissionalizante. Essa realidade requer o conhecimento de muitas normas, regulamentos e procedimentos acadêmicos que dificultam o planejamento destes docentes, que geralmente, não tiveram uma formação para atuar na Educação Profissional e Tecnológica (EPT), conforme apontam estudos de Costa (2012) e Baptaglin (2014). Sabendo que o avanço tecnológico provoca transformações no mundo do trabalho e na educação, estudos de Levy (1999), Luck (2009), Paro (2010), Libâneo (2012), Kensky (2012), Cruz (2016) e Gomes (2017), revelam que as Tecnologias Digitais (TD) podem ser utilizadas pela gestão escolar para: compartilhar informações e conhecimento, otimizar processos e reduzir a formalidade acadêmica. Para facilitar o planejamento docente, esta pesquisa teve como objetivo desenvolver um "Guia Docente", contendo orientações acadêmicas necessárias para o exercício da docência no Instituto Federal de Goiás - Campus Itumbiara. Trata-se de um estudo de caso institucional, descritivo, com abordagem quanti/qualitativa. A população estudada é composta por professores dos cursos técnicos integrados ao ensino médio. Os dados foram coletados por meio de questionários e pesquisa documental. Os dados quantitativos foram analisados por estatística descritiva (BARBETTA, 2012) e os dados qualitativos por Análise de Conteúdo (BARDIN, 2016). Os resultados mostram que existe carência de oferta de formação para a EPT e o uso de um ambiente virtual de aprendizagem para o desenvolvimento de um guia é uma alternativa para a gestão escolar difundir saberes e orientações acadêmicas ao professor, para promover a gestão participativa e a oferta de uma educação profissional de qualidade.
\end{abstract}

Palavras-chave: Educação Profissional. Tecnologias Digitais. Gestão Escolar.

\begin{abstract}
The professors of the Federal Institutes work in different levels of professional education. This reality requires knowledge of many rules, regulations and academic procedures that hinder the planning of these teachers, who generally were not trained to work in Professional and Technological Education (EPT), as indicated by studies by Costa (2012) and Baptaglin (2014). Knowing that technological advances cause changes in working and

\footnotetext{
1 Graduação em Sistemas de Informação pela Universidade Luterana do Brasil (2005), Especialização em Informática na Educação (2011) pela Faculdade do Noroeste de Minas, Mestrado em Educação Profissional e Tecnológica pelo Instituto Federal Goiano - Campus Morrinhos. ORCID ID: https://orcid.org/0000-0002-07732066. E-mail: gilmar.morais@outlook.com

2 Graduação em Ciências da Computação pela Universidade Federal de Goiás (2000), Especialização em Gestão Empresarial (MBA) pela Faculdade CESUC de Catalão, Mestrado em Engenharia Elétrica pela Universidade Federal de Uberlândia (2005) e Doutorado em Engenharia Elétrica pela Universidade Federal de Uberlândia (2011). É professor titular do Instituto Federal Goiano - Campus Morrinhos. ORCID ID: https://orcid.org/00000001-8119-9370. E-mail: fernando.matos@ifgoiano.edu.br
} 
education area, studies by Levy (1999), Luck (2009), Paro (2010), Libâneo (2012), Kensky (2012), Cruz (2016) and Gomes (2017), reveal that Digital Technologies (DT) can be used by school management to: share information and knowledge, optimize processes and reduce academic formality. To facilitate teaching planning, this research aimed to develop a Teaching Guide, using DT, containing academic guidelines necessary for teaching at the Federal Institute of Goiás - Campus Itumbiara. This is an institutional, descriptive case study, with a quantitative / qualitative approach. The studied population is composed by teachers from technical courses integrated to high school education. Data was collected through questionnaires and documentary research. Quantitative data was analyzed using descriptive statistics (BARBETTA, 2012) and qualitative data was analyzed through Content Analysis (BARDIN, 2016). The results show that there is a lack of training offers for EPT and the use of a virtual learning environment for the development of a guiding is an alternative for school management to disseminate academic knowledge and guidance to the professors, to promote participatory management and offer quality professional education.

Keywords: Professional education. Digital Technologies. School management.

\section{Introdução}

A educação só pode ser compreendida dentro de um contexto histórico e social. Com o advento da revolução tecnológica iniciada na década de 1970, ocorreram transformações que reconfiguraram a sociedade, atualmente caracterizada pelo uso das Tecnologias Digitais (TD), em que a interação ocorre por meio de instrumentos como: tablets, smartphones, computadores, videogames, internet. Libâneo (2012) ao abordar os impactos e perspectivas da revolução tecnológica, da globalização e do neoliberalismo no campo educacional, destaca que a educação é elemento central no novo padrão de desenvolvimento econômico, que requer trabalhadores qualificados.

Nenhuma sociedade anterior teve à sua disposição tanta informação, e por isso Lévy (1999) aponta que, no âmbito educacional, o desenvolvimento das TD vem ampliando as alternativas pedagógicas utilizadas no processo de aprendizagem, favorecendo e auxiliando os modelos alternativos de ensino. O fluxo de saber mais veloz e cíclico exige constante aperfeiçoamento e qualificação profissional, ou seja, formação continuada. Os professores e os gestores escolares são profissionais da educação e estão inseridos neste contexto, portanto, também precisam constantemente de formação.

No Brasil, a Lei n ${ }^{\circ}$ 11.741/2008 estabelece que a Educação Profissional e Tecnológica abrange "os cursos de Formação Inicial e Continuada ou qualificação profissional [...]" (BRASIL, 2008a). Por sua vez, o art. $7^{\circ}$ da Lei 11.892/2008 destaca que são objetivos dos Institutos Federais (IF's) "[...] ministrar cursos de Formação Inicial e Continuada de trabalhadores, objetivando a capacitação, o aperfeiçoamento, à especialização e a atualização de profissionais, em todos os níveis de escolaridade, nas áreas da educação profissional e tecnológica" (BRASIL, 2008b). Por isso, os Institutos Federais oferecem várias modalidades de ensino da Educação Básica Técnica e Tecnológica (EBTT), previstas na Lei de Diretrizes e Bases da Educação Nacional, que são: Formação Inicial e Continuada ou Qualificação Profissional, Educação Profissional Técnica de Nível Médio, Educação Profissional Tecnológica de graduação e de pós-graduação.

Essa realidade requer o conhecimento de uma quantidade significativa de normas, regulamentos e procedimentos acadêmicos, que são modificados constantemente pelo avanço tecnológico que incide no contexto educacional, e isso dificulta o planejamento do docente da 

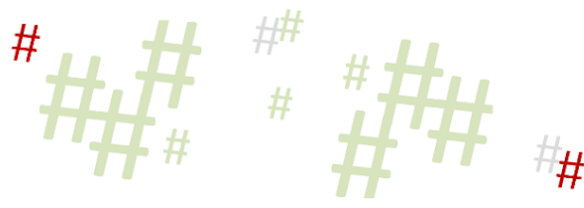

EBTT. Ainda, para estes docentes a necessidade de acompanhar os avanços tecnológicos, se torna ainda maior, pois eles são os responsáveis pela formação dos demais trabalhadores. "Da mesma forma que se espera que a Educação Profissional forme sujeitos autônomos, capazes de gerir seu sustento, o professor também se torna um alvo desse mercado" (OLIVEIRA; GUEDES-PINTO, 2013, p. 123).

Neste contexto, compreende-se que o professor sendo um profissional, precisa de políticas e ações efetivas para sua formação, tendo em vista não só os aspectos pedagógicos, mas também os aspectos normativos, legais e procedimentais da sua profissão. Esse conhecimento é fundamental para promover uma gestão participativa, "o professor precisa conhecer bem a estrutura e a organização do ensino, as políticas educacionais e as normas legais, os mecanismos de sua elaboração e divulgação" (LIBÂNEO, 2012, p. 419). Ainda, "as leis e regulamentos oficiais constituem matéria de conhecimento que a escola e sua equipe não podem ignorar" (LIBÂNEO, 2012, p. 497).

No entanto, são poucas as ações de formação continuada para docentes que tratam de temáticas relacionadas à gestão escolar, e por isso, a aprendizagem normativa, legislativa e procedimental ocorre geralmente de forma colaborativa entre os próprios professores e gestores que têm em comum uma mesma área de atuação. Contribui para complexificar este cenário, a divulgação pulverizada dos documentos acadêmicos, através de e-mail, site, e armazenagem em repositórios distintos, que dificulta muito a integração de professores recém-chegados nos Institutos Federais.

\footnotetext{
Seria útil que a escola dispusesse de síntese atualizada das informações jurídicas e administrativas referentes aos assuntos principais e mais problemáticos da gestão escolar, como: vida funcional de funcionários e professores; regimento interno; diretrizes e normas pedagógicas para questões específicas relacionadas com currículo, planos de trabalho, controles financeiros, etc. (LIBÂNEO, 2012, p. 497).
}

Em geral, os professores da EBTT não tiveram uma formação (inicial ou continuada) para atuar na educação profissional, conforme apontam estudos de Costa (2012) e Baptaglin (2014); por isso não conhecem as suas diretrizes e nem a função social dos Institutos Federais. Ao cursar especialização, mestrado e doutorado em universidades, estes professores adquirem uma formação voltada para à pesquisa e não para a docência. Como o gestor é o responsável pelo cumprimento do projeto político-pedagógico, e muitos cargos são ocupados por professores, isso pode prejudicar a oferta da EPT pelos Institutos Federais.

Segundo Luck (2009, p. 24), "a gestão escolar é o ato de gerir a dinâmica cultural da escola, afinado com as diretrizes e políticas educacionais públicas para a implementação de seu projeto político-pedagógico". Para Libâneo (2012, p. 499) "a direção e a administração da escola são meios para garantir os objetivos educacionais. Dessa forma, uma escola bem organizada administra com eficiência seus recursos materiais e financeiros, assim como o trabalho do seu pessoal". Entende-se que professores/gestores são importantes para que os objetivos da escola sejam atingidos com nível de excelência, por isso também se torna importante que eles conheçam as diretrizes da EPT e a função social dos IF's.

Libâneo (2012) defende o fortalecimento de formas de comunicação e de difusão de informações no ambiente escolar, como característica dos processos de gestão, e observa que a equipe precisa estar informada das diretrizes educacionais, das normas, rotinas administrativas, ou seja, de tudo o que acontece na escola. Como as TD possibilitam o trabalho colaborativo e o compartilhamento de informações e conhecimento, acredita-se que elas podem servir como uma alternativa para a formação continuada de professores em relação às demandas da gestão 
escolar, podendo contribuir para reduzir a formalidade acadêmica e facilitar o planejamento do docente, para se dedicar cada vez mais ao ensino, à pesquisa e à extensão.

\title{
2 Reflexões Teóricas
}

A relação entre ciência e tecnologia busca à produção de bens de consumo e à satisfação das necessidades humanas, assim a tecnologia é uma extensão das capacidades humanas, sendo a mediação entre ciência e produção. A tecnologia "expressa a relação do homem com a natureza e a sua produção, enquanto um ser que se relaciona com os seus instrumentos, com suas ferramentas, com outros seres humanos na relação de trabalho" (MACHADO, 1991, p. 55, apud RODRIGUES, 1998, p. 92). A tecnologia engloba "a prática social; os aprendizados humanos, em seus processos e produtos; o conhecimento empírico, o saber tácito produzido no trabalho; as artes e técnicas desenvolvidas pelos homens; as forças produtivas; as racionalidades e lógicas historicamente produzidas (MACHADO, 2010, p. 86).

Para Castells (1999), as TD são as bases para a "sociedade em rede" ou também conhecida como "sociedade do conhecimento", surgidas a partir da revolução tecnológica iniciada na década de 1970, que possibilitou a globalização e o amplo acesso ao conhecimento. As TD fazem parte do cotidiano e modificam os modos de agir, pensar e se comunicar transformando os nossos comportamentos e a sociedade (KENSKI, 2012). No espaço educacional, as tecnologias são indispensáveis na realização de atividades administrativas e pedagógicas. Historicamente, Almeida (2003) observa que as tecnologias foram incorporadas na educação inicialmente para atender as demandas administrativas e somente mais tarde passaram a ser utilizadas no contexto pedagógico. Hoje, as TD são amplamente utilizadas pelos profissionais que atuam na gestão escolar e trazem benefícios.

\begin{abstract}
$\mathrm{Na}$ contemporaneidade observamos o uso de aplicativos como WhatsApp, por grupos de funcionários, esses aplicativos possibilitam a comunicação em diferentes locais da escola e de forma simultânea. Permitem solucionar problemas de salas de aula; de intervalo escolar, e de horários de entrada e saída de alunos, entre outras. TDIC (Tecnologias Digitais de Informação e Comunicação) aumentam a velocidade de transferência de informações, de cumprimento de metas, de apoio nas secretarias de escola, entre outras finalidades dos processos de gestão e administração escolar (ARXER; INFORSATO, 2018, p. 4).
\end{abstract}

No caso da educação profissional, o trabalho é o princípio educativo ${ }^{3}$ e Rodrigues (1998, p. 62), ao tratar da educação politécnica, reconhece que "o trabalho humano é cada vez mais mediado pela tecnologia, sendo esse um caminho sem retorno". As TD são instrumentos para a inclusão digital, pois possibilitam a acessibilidade e disseminação do conhecimento por meio da internet, permitindo romper as fronteiras e barreiras educacionais através da educação a distância pelo uso de Ambiente Virtuais de Ensino e Aprendizagem, favorecendo a aprendizagem colaborativa e adaptativa. Contudo, algumas preocupações quanto à inserção de TD na educação devem ser observadas como destaca Kenski (2012).

Às Tecnologias Digitais de Comunicação e de Informação, sobretudo o computador e o acesso à internet, começam a participar das atividades de ensino realizadas nas escolas brasileiras de todos os níveis. Em algumas, elas vêm pela conscientização da importância educativa que esse novo meio possibilita. Em outras, são adotadas pela

\footnotetext{
3 Para Gramsci (1982), a forma como a sociedade e o estado se organizam fundamenta-se no trabalho, na sua relação e mediação entre homem-natureza-sociedade. Portanto, o trabalho é quem determina os conteúdos que devem ser aprendidos no ato educativo.
} 
pressão externa da sociedade, dos pais e da comunidade. Na maioria das instituiçõos, no entanto, elas são impostas, como estratégia comercial e política, sem adequação e reestruturação administrativa, sem reflexão e sem a devida preparação do quadro de profissionais que ali atuam (KESNKI, 2012, p. 70).

Machado (2010, p. 95) considera que "a inovação educacional também pode ser vista como objeto de conflitos e de compromissos e, por isso, não pode ser implementada de forma automática, pressupondo sempre negociações entre os interesses envolvidos". Para a transmissão dessas inovações existem fatores intervenientes como a prevalência de hierarquias que impedem a necessária circulação de informações, falta de procedimentos e de investimentos na formação dos profissionais da educação, precariedade da infraestrutura material e pedagógica e falta de suporte técnico. Souza et al. (2017), observa que:

\footnotetext{
Quase que invariavelmente, a tecnologia é vista como um instrumento imprescindível para solução de todos os problemas do homem, e não como uma ferramenta de ação humana [...]. Evidentemente, esse pensamento não é verdadeiro, porque é a partir das mãos humanas que o aparato tecnológico funciona. Isso implica dizer, naturalmente, que sem a mão de obra os computadores e derivados são apenas trabalho morto (SOUZA, et al., 2017, p. 103).
}

Assim, entende-se que a tecnologia não pode e nem deve ser a "protagonista" de qualquer mudança organizacional, mas sim vista com um instrumento, uma ferramenta, um meio, pelo qual as pessoas, se valendo do uso dela, provocam a transformação. Este processo de transformação deve ser estimulado pela gestão escolar, já que as principais atribuições da gestão é garantir o cumprimento das leis, diretrizes e estatuto da instituição de ensino e utilizar as tecnologias da informação para melhorar os processos de gestão em todos os segmentos da escola (LUCK, 2009).

\footnotetext{
Os gestores escolares exercem papel importante na implantação e práticas com novas abordagens de ensino com recursos de TDIC, na mesma vertente, respondem pela eficiência e eficácia da escola a partir desses recursos, enquanto que as tecnologias digitais de informação e comunicação representam a modernização nos processos educativos nas escolas, e, nos processos formativos de gestores, de forma a possibilitar a adequação às demandas da sociedade, em todas as esferas de responsabilidade desse profissional (ARXER; INFORSATO, 2018, p. 6).
}

Aqui, pode-se evidenciar esse papel do gestor na vigilância ao cumprimento dos objetivos da instituição, bem como a sua atuação para a inserção das tecnologias no contexto escolar. Gomes et al. (2017) afirmam que a educação, administração e tecnologias são conceitos atuais e intimamente ligados, e que é preciso refletir sobre qual a melhor forma de usar a tecnologia, e não apenas questionar se esse uso é ou não adequado. Se a sociedade contemporânea é cercada pelas TD é fundamental "que a escola esteja apta a lidar com tais recursos, de forma a potencializar ao máximo suas ações administrativas e pedagógicas" (GOMES et al.,2017, p. 2).

No entanto, é perceptível nos ambientes escolares uma utilização de TD concentrada em sistemas informacionais que se destinam exclusivamente para fins de organização administrativa, tendo, em segundo plano, aplicação na organização pedagógica. Paro (2010) alerta sobre essa distinção, comum nas escolas, entre as atividades pedagógicas e administrativas, "como se o administrativo e o pedagógico não pudessem coexistir numa mesma atividade - , encobrindo assim o caráter necessariamente administrativo de toda prática pedagógica e desconsiderando as potencialidades pedagógicas da prática administrativa" (PARO, 2010, p. 766). 
Ainda, Paro (2010), ao fazer uma reflexão em relação a racionalização do trabalho no ambiente escolar, observa que há dois tipos de recursos envolvidos na busca dos propósitos organizacionais: os objetivos e os subjetivos. O primeiro refere-se aos instrumentos, aos elementos, aos materiais envolvidos no processo escolar, já o segundo se refere à capacidade de trabalho humano. Esses recursos não agem de forma dissociada, mas se integram e se articulam. No caso do Institutos Federais (IF’s), que são instituições públicas de ensino, entende-se que a TD é um recurso "objetivo" e os professores/gestores são recursos "subjetivos", e a relação entre ambos é necessária para cumprir a missão dessas instituições, que é ofertar educação profissional e tecnológica de forma gratuita e de qualidade.

A lei 11.892/2008 que trata da criação dos Institutos Federais estabelece em seus art. $7^{\circ}$ e $8^{\circ}$ a oferta de $50 \%$ de suas vagas para educação profissional técnica de nível médio, prioritariamente na forma de cursos integrados, para os concluintes do ensino fundamental e para o público da educação de jovens e adultos. Tendo em vista esta atribuição, Ciavatta (2005), Moura (2007) e Ramos (2007), entre outros, apontam a integração do ensino médio com a educação profissional como um caminho possível para romper com a dualidade entre educação propedêutica e educação profissional. Para Frigotto, Ciavatta e Ramos (2012, p. 45) essa possibilidade de integrar a formação geral e técnica no ensino médio, objetivando a formação integral do ser humano, é uma "condição necessária para a travessia em direção ao ensino médio politécnico e à superação da dualidade educacional pela superação da dualidade de classes".

No entanto, ainda é perceptível a existência dessa dualidade na rede federal, seja pela forma de oferta dos cursos ou até mesmo na não integração dos currículos. Para Costa (2012, p. 38) a implementação do ensino médio integrado vai além das questões pedagógicas e do projeto curricular, pois exige "a superação de diversos desafios dentre eles os de gestão; pedagógicos; condições de ensino; condições materiais; hábitos estabelecidos culturalmente que limitam a formação integrada dos alunos". Para promover uma formação adequada aos alunos do ensino médio integrado ao técnico é preciso que os professores tenham uma formação que lhe permite cumprir essa atribuição, ou seja, é imprescindível que os profissionais que atuam na EPT tenham conhecimento sobre as bases conceituais e os princípios norteadores da educação profissional, e isso requer a adoção de políticas e ações de formação de professores.

Ao tratar de políticas e ações de formação de professores para atuar na EPT, surgem algumas "controvérsias". Costa (2012) observa que essas políticas se configuraram ao longo da história como programas de governos e não como política de Estado. Como as licenciaturas não são requisitos para o exercício da docência nos cursos técnicos, são desenvolvidas ações isoladas com o intuito de promover profissionais não docentes para exercerem a docência, como programas e ações de formação continuada para professores bacharéis ou técnicos de forma emergencial, imediatista, aligeirada, descontinuada, fragmentada e superficial, já que não abarcam questões pedagógicas próprias da EPT.

Com o intuito de apreender e problematizar as políticas públicas para a formação de professores para a EPT, Meneses Filho e Costa (2017) realizaram estudo da legislação brasileira entre 1917 e 2017 (cem anos), e constataram que a legislação é flexível quanto à formação de professores, permitindo cursos emergenciais e especiais, por outro lado, não evidencia a obrigatoriedade da licenciatura. A educação profissional em sua história, como também a formação dos professores para a EPT, não refutou a lógica mercadológica capitalista e neoliberal, o que vem contribuindo para uma educação que não cumpre totalmente com a sua missão social (COSTA, 2012).

Ainda, com a criação da Rede Federal em 2008, os Institutos Federais passaram a oferecer cursos de Licenciatura, no entanto, estes cursos apresentam conteúdos similares aos 
ofertados pelas universidades, e preparam o professor para atuar na educação básica e não na educação profissional. INEP (2008) aponta que há uma diferenciação dos IFs das outras instituições federais de ensino pela oferta explícita da EPT, mas percebe-se uma negação da diferenciação quando o assunto é a prática da própria instituição que não oferta formação específica para seus docentes, tais contradições culminam com a questão da rede federal claramente se eximir do papel de formar seus professores por questões políticas, sociais e técnicas.

É claro que existem ações isoladas, no sentido se trazer formação e conhecimentos pedagógicos para a formação de professores da EPT, no entanto, não se constituem como política pública. Ainda, para atuação nos cursos técnicos integrados ao ensino médio são necessários conhecimentos pedagógicos e prática educativa específica para promover a integração e interação entre as disciplinas da formação técnica e geral.

A formação de professores para a educação profissional ainda não tem os rumos bemdefinidos. Essa falta de rumo, de certa forma, prejudica tanto o professor como os alunos, que necessitam de professores competentes tanto em relação ao domínio dos conhecimentos didáticos pedagógicos quanto ao domínio dos conhecimentos técnicos e políticas da área (STRYHALSKI; GESSER, 2017, p. 98).

Outros pesquisadores citados em INEP (2008), como Regina Gracindo, Maria Rita, Dante Moura, Eloisa Helena Santos, Monteiro e Pereira, também convergem que é emergencial e necessária a formação de professores para a EPT e que essa formação deve ser ofertada preferencialmente em cursos de licenciatura e/ou especialização. Também há um consenso de que a maioria dos cursos de mestrado e doutorado formam professores com foco na pesquisa, sem formação pedagógica, e somente a experiência, sem a necessidade da referida formação pedagógica, seria insuficiente para ser um docente.

$\mathrm{Na}$ falta de políticas específicas por parte do governo, para a formação de professores para atuarem na EPT, uma alternativa é modificar os editais dos concursos para docentes na Rede Federal, com o intuito de valorizar os candidatos que possuem Licenciatura ou Pedagogia e exigir conhecimento em EPT. Com a expansão da Rede Federal houve um ingresso de muitos professores mestres e doutores, porém, tendo ingressado na rede com esse nível de formação, estes professores não se sentem na necessidade de fazer uma pós-graduação em EPT, muito menos uma licenciatura. Alguns IF's inclusive já têm elaborado editais com pontuação específica para licenciados e exigido, durante o estágio probatório, formação pedagógica para os não-licenciados, para tentar melhorar esse cenário.

Apesar dos debates sobre o tema terem iniciado em 2004 e ocorrido o Seminário de 2006 (INEP, 2008), a tese de Costa (2012) conclui que de 2004 a 2012 (8 anos), foram restritos e pouco significativos os avanços na formação de professores para a EPT. Atualmente, algumas instituições da rede federal como Instituto Federal do Triângulo Mineiro - IFTM, Instituto Federal de Santa Catarina - IFSC, Instituto Federal Baiano - IFB ofertam Licenciatura em Educação Profissional e Tecnológica. O Instituto Federal de Goiás - IFG oferta curso de formação pedagógica para os professores não-licenciados e Especialização em Políticas e Gestão da Educação Profissional e Tecnológica. Já o Instituto Federal do Rio Grande do Norte - IFRN oferta Especialização em Educação Profissional e Tecnológica.

Em 2017, o Conselho Nacional das Instituições da Rede Federal de Educação, Científica e Tecnológica - CONIF, com o apoio da Secretaria de Educação Profissional e Tecnológica - SETEC, incentivou a proposição do Mestrado Profissional em Educação Profissional em Rede Nacional (ProfEPT), em função da necessidade de aperfeiçoar as práticas educativas e a gestão escolar vinculadas à EPT, sendo que $50 \%$ de suas vagas são destinadas 
aos servidores ativos das instituições que compõem a Rede Federal de Educação Profissional, Científica e Tecnológica. Em 2020, o ProfEPT ofereceu 913 vagas, distribuídas em 40 polos (instituições associadas) espalhados por todo o território brasileiro.

Isso demonstra que a partir de 2012 algumas políticas e ações institucionais têm sido realizadas, mesmo que de forma tímida e insuficiente, mas que podem servir de modelo. Portanto, fica a questão: Diante das políticas atuais, com oferta de formação pedagógica, licenciatura e especialização para formação em EPT, quando atingiremos uma totalidade de professores atuando na EPT com formação adequada para a esta modalidade? Baptaglin (2014) observa que "a aprendizagem da docência na EPT ainda é bastante incipiente", existe uma carência de pessoal qualificado, que inclusive prejudica não só a oferta quanto à expansão da EPT no Brasil. Daí a importância em se difundir conceitos, diretrizes, princípios e políticas da EPT, principalmente, aos professores que atuam nessa modalidade de ensino.

Para ampliar esse processo de formação de professores e de difusão das diretrizes da EPT, julga-se necessária a adoção de outros mecanismos, canais de comunicação e tecnologias pela gestão escolar. Se os sistemas informacionais são instrumentos que se integram ao processo de trabalho do professor e do gestor escolar, questiona-se a falta de sistemas direcionados para formação do professor e auxiliar no planejamento e organização extra sala de aula. Algumas ações estão sendo realizadas neste sentido, como o estudo de Cruz (2016) que desenvolveu um curso de formação continuada sobre a legislação educacional, denominado "Formação Normativa", que foi elaborado na Wiki.

O produto proposto por Cruz (2016) foi reconhecido entre os participantes como um instrumento facilitador da capacitação docente no meio escolar e oportunizou e fomentou a participação na construção da análise da legislação educacional. A formação ofertada por meio da Wiki ofereceu aos participantes um crescimento profissional para melhorar seus planejamentos e principalmente buscar seus direitos de docentes.

Quando os gestores e os profissionais estão a par do que ocorre na escola e quando há o compartilhamento de informações, os problemas podem ser solucionados com maior facilidade. Contudo, a gestão democrática tem que acontecer e não apenas ficar escrita nos documentos oficiais da escola. Cabe ao gestor iniciar o processo de promoção dessa mudança cultural de instrumentalização da participação das instâncias escolares (CRUZ, 2016, p. 78).

Nestes estudos, o desconhecimento dos professores em relação a tecnologia é a principal dificuldade encontrada para o seu uso no processo de formação. Por isso, é fundamental que durante o processo de escolha de instrumentos tecnológicos para a formação docente, que sejam preferidos aqueles que os professores estão mais familiarizados. Todo este contexto motivou a realização desta pesquisa, cujo percurso metodológico será apresentado a seguir.

\section{Percurso Metodológico}

Este estudo possui uma abordagem quanti-qualitativa, de tipo descritivo, e o método utilizado foi o estudo de caso institucional. O percurso metodológico pode ser visto em forma de fluxograma na Figura 1. A pesquisa foi realizada no Instituto Federal de Goiás - IFG, especificamente no campus Itumbiara. Martins e Theóphilo (2009) esclarecem que a população é o conjunto de indivíduos que apresenta em comum determinadas características definidas para o estudo, já a amostra é um subconjunto da população, conforme algum critério de representatividade. A população deste estudo foi constituída por 38 docentes que atuam em dois Cursos Técnicos Integrados ao Ensino Médio (Química e Eletrotécnica). 
Uma vez estabelecida a população, o próximo passo foi dimensionar o tamanho da amostra. A utilização de uma amostra implica na aceitação de uma margem de erro denominada Erro Amostral. Quanto maior a amostra, menor é o Erro Amostral, e vice-versa, ou seja, são grandezas inversamente proporcionais. Sabendo que a população é "finita", o tamanho da amostra (n) foi estabelecido com base na estimativa da proporção populacional (TRIOLA, 1999). Considerando um nível de confiança de $90 \%(Z \alpha / 2=1,65)$, proporção amostral de indivíduos pertencentes a categoria em 0,5 , uma margem de erro de estimativa em $10 \%$, e população de 38 docentes, tem-se uma amostra de 26 docentes.

Para coleta de dados foi utilizada pesquisa documental e questionários autoaplicáveis elaborados com base nas exigências da Resolução no 466/2012 do Ministério da Saúde, para isto, esta pesquisa foi submetida e devidamente aprovada por Comitê de Ética em Pesquisa CEP. A pesquisa documental permitiu fazer o levantamento dos documentos (normas, regulamentos, procedimentos) necessários para o trabalho docente, que foram disponibilizados no Guia Docente (produto educacional). A pesquisa documental ocorreu por meio de consulta "in loco" à Coordenação Acadêmica e Coordenadores de Cursos. O pesquisador apresentou os objetivos da pesquisa aos coordenadores e solicitou que eles relacionassem aos documentos, normas, regulamentos e procedimentos utilizados pelos professores, para serem disponibilizados no guia.

$\mathrm{Na}$ fase de diagnóstico foi aplicado questionário para professores, com o intuito de obter informações para subsidiar o desenvolvimento do produto educacional. Na fase de validação do produto foi aplicado um segundo questionário para saber a opinião dos professores quanto à funcionalidade do Guia Docente. Os questionários foram elaborados por meio do aplicativo Formulários Google (Google Forms), que é um aplicativo de administração de pesquisas. Para Severino (2007, p. 125), questionário é um "conjunto de questões, sistematicamente articuladas, que se destinam a levantar informações escritas por parte dos sujeitos pesquisados, com vistas a conhecer a opinião dos mesmos sobre os assuntos em estudo".

Figura 1 - Fluxograma do Percurso Metodológico

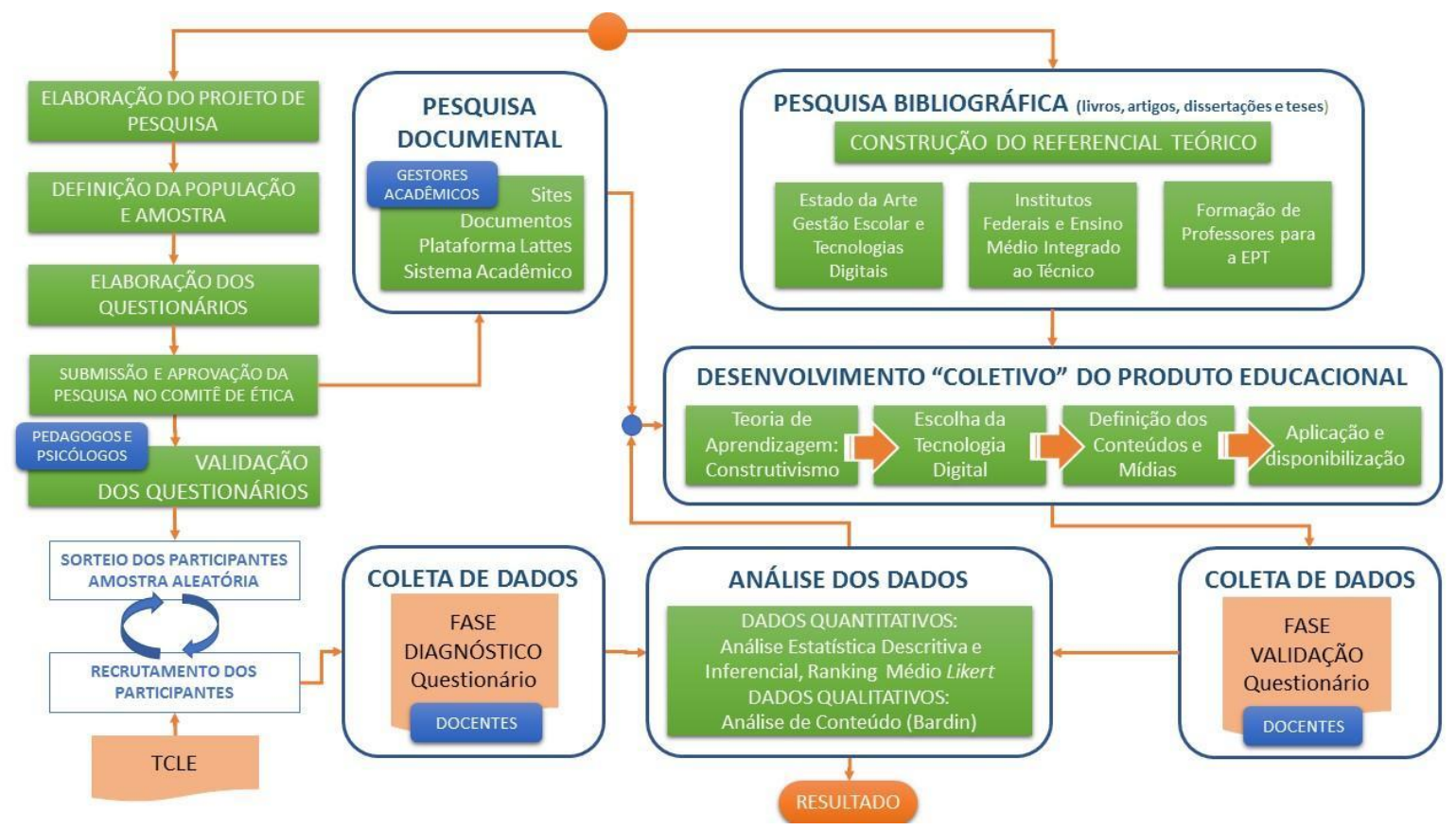

Fonte: Elaborado pelo autor (2019). 
Os questionários foram constituídos por questões abertas e fechadas, combinados com questões utilizando a escala de Likert, de resposta psicométrica muito utilizada em questionários que pretendem identificar atitudes e opiniões acerca de determinado objeto. Neste tipo de questionário é solicitado que os respondentes indiquem seu grau de concordância ou não, em relação a um objeto de análise. As respostas desta escala vão de "discordo totalmente" a "concordo totalmente", podendo variar de três a dez itens de resposta (ALMEIDA; BOTELHO, 2009). O questionário abrangeu questões relacionadas ao acesso e compartilhamento de informações na instituição, percepção dos professores em relação às TD, compreensão acerca das diretrizes da EPT e a função social dos IF's.

Antes de sua aplicação, os questionários foram submetidos a dois psicólogos e cinco pedagogos, todos servidores do IFG campus Itumbiara, para validação de conteúdo para comprovar se os itens apresentados estão de acordo com a proposta da pesquisa. Gil (2010), Marconi e Lakatos (2003) sugerem os seguintes fatores a serem avaliados em um questionário: formatação, objetividade, clareza dos termos, compreensão dos conteúdos, linguagem acessível para o entendimento das questões, ordenamento e quantidade de perguntas / pontos a serem avaliados. O objetivo da validação foi constatar se o instrumento da pesquisa garante resultados isentos de erros, se as questões foram elaboradas com clareza, de fácil entendimento, se não há indução e se são adequadas ao problema da pesquisa. Após período de 15 dias, os questionários haviam sido validados por dois psicólogos e dois pedagogos.

De forma concomitante a etapa de validação, foi iniciada a etapa de recrutamento de participantes para a pesquisa. Para obter uma amostra aleatória de professores foi utilizado um método de Amostragem Probabilística, que seleciona os indivíduos da população de forma que todos tenham as mesmas chances de participar da amostra (BARBETTA, 2012). Os elementos da população são rotulados e os indivíduos que farão parte da amostra são sorteados. Cada participante recebeu um número de identificação, iniciando em 1 até o limite da população. $\mathrm{O}$ sorteio foi realizado no site sorteador.com.br, que possibilita inserir a quantidade necessária de participantes (amostra) e o tamanho da população. De acordo com os números sorteados, foi se estabelecendo uma sequência para recrutamento dos participantes da pesquisa.

Para recrutar os professores, o pesquisador fez uma breve apresentação da pesquisa, e os professores que aceitaram participar da pesquisa receberam o TCLE para leitura, preenchimento e assinatura. Nesta fase foi dado o prazo de 5 dias para devolução dos termos para o pesquisador. Esse processo se repetiu até atingir a quantidade necessária prevista para amostra ou esgotar o limite da população. Após, os questionários foram aplicados, e os dados coletados foram analisados da seguinte forma: os dados quantitativos foram tabulados no software de elaboração de planilhas eletrônicas da Microsoft (Excel) e realizada análise estatística descritiva e inferencial; os dados qualitativos foram analisados usando Análise de Conteúdo de Bardin (2016), que é um conjunto de técnicas de análise das comunicações, por meio de procedimentos sistemáticos e objetivos de descrição do conteúdo das mensagens.

A maioria das questões utilizou escala tipo Likert de 5 pontos, para mensurar o grau de concordância dos participantes da pesquisa. Para a análise dos resultados destas questões foi realizada uma abordagem quantitativa para estabelecer o Ranking Médio (RM). Para calcular do RM, faz-se a média ponderada, para cada um dos itens do questionário, dividindo-as pelo número total de participantes (NP) respondentes do questionário (OLIVEIRA, 2005). Ou seja, o Ranking Médio é calculado pela equação: $R M=\sum(F . V) /(N P)$, em que: $F=$ frequência observada de cada resposta para cada afirmação, $\mathrm{V}=$ valor de cada resposta, $\mathrm{NP}=$ número de participantes. 
Cada resposta possui o seguinte valor para V: Discordo Totalmente $=1$, Discordo Parcialmente $=2$, Indiferente $=3$, Concordo Parcialmente $=4$ e Concordo Totalmente $=5$. Quanto mais próximo o RM estiver de cinco, maior será o nível de concordância dos participantes quanto à afirmação, e quanto mais próximo de um, menor será essa concordância. Foram considerados os seguintes resultados para o RM: até 1,5 como "Discordo totalmente"; 1,6 até 2,7 como "Discordo Parcialmente"; de 2,8 até 3,2 como "Indiferente"; entre 3,3 até 4,5 como "Concordo Parcialmente"; e a partir de 4,6 como "Concordo Totalmente".

\section{Resultados e Discussões}

Participaram da pesquisa 25 docentes que garante aos resultados um grau de confiança de $90 \%$ e margem de erro de $9,78 \%$. Estes participantes possui o seguinte perfil: 15 do sexo masculino e 10 do sexo feminino, idades que variam de 28 a 56 anos, sendo que 24 possuem idade acima de 30 anos, 15 são doutores, 09 são mestres e 01 é especialista. Quanto ao tempo de trabalho no campus Itumbiara 05 docentes responderam que trabalham há mais de 10 anos, 14 docentes há mais de 05 anos e apenas 06 docentes trabalham tempo inferior a 05 anos.

Quanto à instituição em que estes docentes cursaram a graduação 22 responderam que cursaram em instituições públicas (universidades federais e estaduais) e apenas 03 cursaram a graduação em instituições particulares. Nenhum professor participante da pesquisa cursou graduação em Institutos Federais, CEFET ou Escolas Técnicas. Foi questionado qual a área de formação e qual a área de atuação do docente, tendo em vista a tabela de áreas do conhecimento da CAPES, o resultado mostrou que a totalidade dos participantes atuam na mesma área de sua formação, ou seja, não há "desvio" para atuação em outras áreas equivalentes.

Quanto à atuação na gestão 16 docentes responderam que nunca ocuparam cargos de gestão no IFG, 07 exerceram a função de coordenador de curso, 01 de coordenador acadêmico e 01 de gestor do Programa Mulheres Mil. Dos 25 docentes participantes da pesquisa, 15 já exerceram outra profissão antes de ingressar no IFG e 10 sempre foram docentes. Foi possível constatar que dos professores que nunca exerceram outra profissão 03 são da área profissionalizante (engenharia elétrica), ou seja, estes não tiveram experiência no mundo do trabalho. Ainda, 18 professores afirmaram que nunca atuaram no ensino profissionalizante antes de ingressar no instituto federal.

A pesquisa apurou a percepção dos docentes sobre o processo de compartilhamento e acesso à informação, neste sentido, sobre a afirmação "você tem necessidade de buscar as informações que precisa, para o seu trabalho como professor, diretamente nos setores acadêmicos e administrativos", 03 participantes "concordaram totalmente", 16 "concordaram parcialmente", 04 ficaram "indiferente", 02 "discordaram totalmente". O ranking médio obtido para essa afirmação foi " 3,72 ", ou seja, os docentes "concordam parcialmente". Sobre a questão "qual é o nível de dificuldade para acessar documentos, orientações, normas, procedimentos e regulamentos necessários para o seu trabalho como professor?", 03 participantes responderam "muito fácil", 12 "fácil", 04 "neutro", 05 "difícil", 01 "muito difícil". O ranking médio obtido para essa questão foi " 3,44 ", ou seja, os docentes consideram "fácil".

Sobre a afirmação "Você tem dificuldade para encontrar as informações que precisa no site do IFG", 04 participantes "concordaram totalmente", 15 "concordaram parcialmente", 01 ficou "indiferente", 04 "discordaram parcialmente", 01 "discordou totalmente". O ranking médio obtido para essa afirmação foi " 3,68 ", ou seja, os docentes "concordam parcialmente". Quanto à questão "Tendo em vista a execução do trabalho docente, como você classifica o nível de formalidade dos procedimentos acadêmicos do IFG Campus Itumbiara?", 14 participantes 
responderam "adequado", 02 ficaram "indiferente", 09 "inadequado". O ranking médio obtido para essa questão foi " 3,2 ", ou seja, os docentes consideram "indiferente".

Quanto à questão "Como você classifica a divulgação de informações acadêmicas, necessárias para a atividade docente no IFG Campus Itumbiara?", 02 participantes responderam "muito adequado", 13 "adequado", 04 "indiferente", 05 "inadequado", 01 "muito inadequado". O ranking médio obtido para essa afirmação foi "3,4", ou seja, os docentes consideram "adequado". Ainda, 12 docentes afirmaram que já utilizaram algum documento institucional desatualizado, 08 docentes responderam "talvez" e apenas 05 nunca utilizaram.

A pesquisa também buscou identificar a percepção sobre as TD, para isso os participantes responderam a seguinte afirmação "Você tem dificuldade para utilizar os sistemas de informação (Visão, Q-acadêmico, SUAP, SUGEP) do IFG", sendo que 15 "concordaram parcialmente", 03 "discordaram parcialmente" e 07 "discordaram totalmente". O ranking médio obtido para essa afirmação foi "2,92", ou seja, os docentes consideram "indiferente". Sobre a periodicidade de utilização do e-mail institucional, 21 participantes responderam que usam diariamente, 03 semanalmente e 01 quinzenalmente.

Também foi avaliada a periodicidade de acesso ao site do IFG e 04 participantes responderam que acessam diariamente, 14 semanalmente, 4 quinzenalmente, 01 mensalmente e 02 professores não utilizam o site. Quanto à frequência de utilização do Ambiente Virtual de Aprendizagem - AVA (Moodle), 01 participante respondeu que utiliza "semanalmente", 01 "quinzenalmente", 06 "mensalmente", 17 não utilizam o AVA. O AVA Moodle possui uma versão mobile e por isso foi questionado se os docentes a utilizam, 01 docente respondeu que sim e 24 responderam que não utilizam a versão mobile.

Um dos objetivos específicos desta pesquisa é identificar se os professores receberam formação inicial e/ou continuada para atuar na EPT e se eles reconhecem, promovem a função social dos institutos federais. Para isso, os participantes foram indagados sobre "Como você classifica o seu conhecimento acerca das diretrizes da Educação Profissional e Tecnológica?" e 02 participantes responderam "excelente", 04 "ótimo", 09 “bom”, 07 "regular", 03 "ruim". O ranking médio obtido para essa questão foi " 2,8 ", ou seja, os docentes consideram "bom". Também foi questionado em que fase de formação o docente aprendeu as diretrizes da EPT (Gráfico 1), e ampla maioria respondeu que foi “estudando para o concurso público".

Gráfico 1 - Fase da formação em que o docente aprendeu sobre as diretrizes da EPT

\section{Em que fase de formação você aprendeu sobre as diretrizes da EPT?}

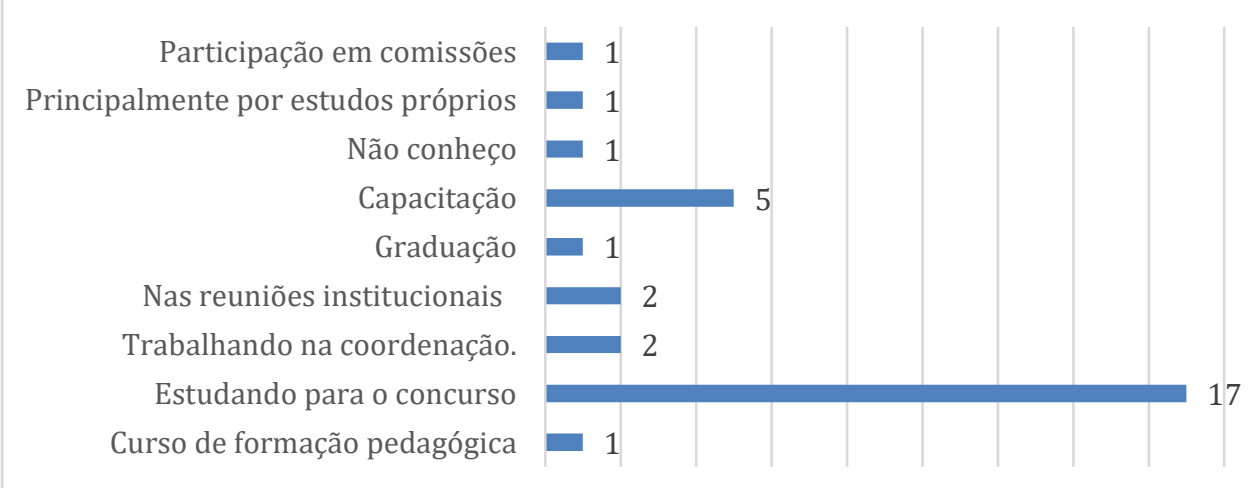

Fonte: Elaborado pelo autor (2020). 
No intuito de compreender melhor o conhecimento dos participantes em relação a EPT e sabendo que o trabalho como princípio educativo é uma diretriz básica dessa modalidade de educação, foi realizada a seguinte pergunta: “O que é trabalho como princípio educativo?”. Por se tratar de uma questão aberta foi realizada a análise de conteúdo das respostas, usando a técnica denominada "análise categorial", tendo como referência Bardin (2016). Essa técnica consiste no desmembramento do texto em categorias agrupadas analogicamente, que são construídas em etapas: seleção do material, leitura flutuante, codificação.

$\mathrm{Na}$ etapa de codificação foram constituídas unidades de registro pela repetição de palavras, e a partir dessas unidades foi realizada a categorização progressiva (inicial, intermediária e final). As categorias iniciais foram constituídas na etapa de "leitura flutuante" das respostas, em que foram selecionados os trechos e palavras-chaves mais significativos. Para refinar a análise dos dados, o agrupamento progressivo das categorias iniciais intermediárias e finais foi realizado a partir de "análise temática" (Quadro 1). Após a análise, obteve-se 19 categorias iniciais, 07 categorias intermediárias e 03 finais.

Quadro 1 - Categorias de análise de conteúdo - Trabalho como princípio educativo

\begin{tabular}{|c|c|c|c|}
\hline & Categorias Iniciais & $\begin{array}{c}\text { Categorias } \\
\text { Intermediárias }\end{array}$ & Categorias Finais \\
\hline 1 & Trabalho orienta o processo educativo & \multirow{5}{*}{$\begin{array}{l}\text { Trabalho é um processo } \\
\text { formativo }\end{array}$} & \multirow{8}{*}{$\begin{array}{l}\text { Prática educativa } \\
\text { orientada pelo } \\
\text { trabalho }\end{array}$} \\
\hline 2 & Trabalho orienta a prática educativa e o currículo & & \\
\hline 3 & Trabalho como forma de educar & & \\
\hline 4 & Atividade laboral como processo educativo e formativo & & \\
\hline 5 & Trabalho é formativo e próprio do ser humano & & \\
\hline 6 & $\begin{array}{l}\text { Utilização das experiências de trabalho como ferramenta } \\
\text { para formação }\end{array}$ & \multirow{3}{*}{$\begin{array}{l}\text { Trabalho é experimental } \\
\text { e prático }\end{array}$} & \\
\hline 7 & Aprender durante o exercício do trabalho & & \\
\hline 8 & Aprender pelo trabalho & & \\
\hline 9 & $\mathrm{O}$ trabalho educa e liberta para o convívio em sociedade & \multirow{4}{*}{$\begin{array}{l}\text { O trabalho emancipa o } \\
\text { sujeito }\end{array}$} & \multirow{7}{*}{$\begin{array}{l}\text { Educação pelo } \\
\text { trabalho }\end{array}$} \\
\hline 10 & Formar para o trabalho numa perspectiva emancipatória & & \\
\hline 11 & $\begin{array}{l}\text { Educar o estudante trabalhador, a partir de sua realidade, } \\
\text { em relação às técnicas de trabalho para promover } \\
\text { emancipação }\end{array}$ & & \\
\hline 12 & Formação educacional integral do sujeito/indivíduo & & \\
\hline 13 & $\begin{array}{l}\text { Caráter formativo do trabalho e da educação como uma } \\
\text { ação humanizadora que contempla aspectos materiais e } \\
\text { socioculturais }\end{array}$ & \multirow{2}{*}{$\begin{array}{l}\text { O trabalho humaniza o } \\
\text { homem }\end{array}$} & \\
\hline 14 & $\begin{array}{l}\text { O trabalho é uma atividade educativa e formativa que } \\
\text { desenvolve o sujeito pela formação integral, } \\
\text { humanizadora, politécnica }\end{array}$ & & \\
\hline 15 & Relação indissociável de saber/fazer, (teoria/prática) & $\begin{array}{l}\text { O trabalho é práxis } \\
\text { saber/fazer. }\end{array}$ & \\
\hline 16 & Relação escola e empresa & \multirow{3}{*}{$\begin{array}{l}\text { Formação para o } \\
\text { mercado de trabalho }\end{array}$} & \multirow{4}{*}{$\begin{array}{l}\text { Formação para o } \\
\text { trabalho }\end{array}$} \\
\hline 17 & Preparação para as profissões do mercado & & \\
\hline 18 & Educar para o trabalho & & \\
\hline 19 & Domínio de conhecimentos técnicos e normativos & Formação Técnica & \\
\hline
\end{tabular}

Fonte: Elaborado pelo autor (2020)

A primeira categoria foi constituída a partir das respostas de 08 participantes, que entendem que o "trabalho como princípio educativo" é uma "prática educativa orientada pelo trabalho". Para estes, o "trabalho" é visto como uma forma didática que pode direcionar o processo educativo. Estes participantes também valorizam o aspecto experimental do trabalho, 
ou seja, "aprende-se fazendo". A segunda categoria foi constituída a partir das respostas de 07 participantes, que consideram a relação do trabalho com a educação necessária para formação integral do aluno, que objetiva a sua emancipação por meio de uma formação humanizadora, técnica, científica e sociocultural, ou seja, o saber técnico não pode ser dissociado de reflexão. Ainda, antes de se tornar um "profissional", o aluno deve se tornar cidadão capaz de compreender a sua realidade e promover transformação social. A terceira categoria foi constituída a partir das respostas de 04 participantes que compreendem o "trabalho como princípio educativo" como a formação para o trabalho, tendo como objetivo a empregabilidade e o mercado de trabalho, ou seja, "educa-se para trabalhar". Dos 25 participantes, 04 não souberam responder essa pergunta e 02 responderam de forma rasa e descontextualizada.

Para Ciavatta (2005) e Brasil (2007), a educação geral e a educação profissional são indissociáveis, ou seja, é preciso compreender que o trabalho é um princípio educativo necessário para superar a dicotomia trabalho manual / trabalho intelectual e incorporar a dimensão intelectual ao trabalho produtivo, para assim, formar trabalhadores capazes de atuar como dirigentes e cidadãos. Busca-se transpor uma formação reducionista que objetiva a preparação para o trabalho em seu aspecto operacional, desprovido dos conhecimentos científicos e tecnológicos e de sua apropriação histórico-social.

Em Brasil (2010), a educação deve abranger todas as dimensões educativas, sejam elas: social, política e produtiva. Para isso é necessário reconhecer o trabalho como princípio educativo e como categoria orientadora das políticas da educação profissional e tecnológica. A formação do trabalhador deve contemplar os fundamentos, princípios científicos e linguagens das tecnologias que caracterizam o processo de trabalho contemporâneo, numa perspectiva histórica, para tornar esse cidadão um agente político capaz de compreender a realidade e promover as transformações políticas, econômicas, culturais e sociais.

O Projeto Político Pedagógico Institucional (PPPI) do IFG, elaborado em 2018, prevê que o trabalho é uma categoria central para promover uma educação que busca a formação profissional e tecnológica. Este documento reconhece que o trabalho é a forma particular de produção da própria vida humana e envolve a construção de meios de subsistência física e cultural. Para isso, a formação acadêmica requer o trabalho como lócus de produção do conhecimento e como princípio educativo.

Esperava-se respostas que se aproximassem aos conceitos descritos em Gramsci (1982), Ciavatta (2005), Brasil (2007), Brasil (2010) e no PPPI do IFG. O resultado apresentado mostra que 7 participantes compreendem o conceito de "trabalho como princípio educativo" e 18 não compreendem de forma adequada, sendo que destes, 15 possuem formação em áreas das "ciências exatas e da terra" ou "engenharias". Por este resultado, evidencia-se a necessidade de discutir essa temática com os professores para oferecer formação específica.

Quanto à função social do IFG, 17 participantes afirmaram que já realizaram e/ou realizam alguma ação social e 08 participantes responderam "talvez". Essa dúvida de ter ou não promovido alguma ação social por parte de alguns docentes traz a reflexão se de fato estes docentes conhecem essa função social. Para esclarecer essa dúvida, foi previsto no questionário a seguinte pergunta: "Qual é a função social dos Institutos Federais?". Por se tratar de uma questão aberta, também foi realizada a análise de conteúdo, usando a técnica "análise categorial", tendo como referência Bardin (2016). Após a análise, foram obtidas 11 categorias iniciais, 05 categorias intermediárias e 03 finais, conforme Quadro 2.

A primeira categoria pressupõe que a função social dos IF é "Preparar para a cidadania", ou seja, é função do IF preparar os sujeitos para o exercício pleno da sua cidadania, e isso requer uma formação integral, que abarque conceitos éticos, morais; bem como saberes técnicos e 
científicos. A segunda categoria pressupõe que a função social dos IF é "Ampliar a oferta e o acesso à educação pública e profissional", ou seja, ampliar o acesso que antes ficava restrito às regiões metropolitanas. A terceira categoria pressupõe que a função social dos IF é "Ofertar EPT para a transformação social". Ao relacionar as categorias encontradas com Brasil (2010), Souza e Machado (2017) e a Lei $n^{\circ} 11.892 / 2008$, que criou os Institutos Federais, pode-se afirmar, que os professores participantes, em sua ampla maioria, compreendem a função social dos Institutos Federais.

Quadro 2 - Categorias de análise de conteúdo - Função social dos IF's

\begin{tabular}{|c|c|c|c|}
\hline \multicolumn{2}{|r|}{ Categorias Iniciais } & $\begin{array}{c}\text { Categorias } \\
\text { Intermediárias }\end{array}$ & Categorias Finais \\
\hline 1 & Ofertar formação ampla & \multirow{3}{*}{$\begin{array}{l}\text { Formação crítica e } \\
\text { integral do cidadão }\end{array}$} & \multirow{3}{*}{$\begin{array}{c}\text { Preparar para a } \\
\text { cidadania }\end{array}$} \\
\hline 2 & Ofertar formação integral & & \\
\hline 3 & Ofertar formação crítica e cidadã & & \\
\hline 4 & Oferecer educação pública, gratuita e de qualidade & \multirow{2}{*}{$\begin{array}{l}\text { Ampliar o acesso à } \\
\text { educação pública }\end{array}$} & \multirow{4}{*}{$\begin{array}{c}\text { Ampliar a oferta e } \\
\text { o acesso à educação } \\
\text { pública e } \\
\text { profissional }\end{array}$} \\
\hline 5 & Interiorizar a oferta de educação pública de qualidade & & \\
\hline 6 & Ofertar 50\% vagas ensino técnico & \multirow{2}{*}{$\begin{array}{l}\text { Ampliar a oferta de } \\
\text { educação profissional }\end{array}$} & \\
\hline 7 & Oferecer formação técnica e tecnológica & & \\
\hline 8 & Contribuir com a sociedade & Melhorar as & \multirow{4}{*}{$\begin{array}{l}\text { Ofertar EPT para a } \\
\text { transformação } \\
\text { social }\end{array}$} \\
\hline 9 & Promover ações para melhorar a qualidade de vida & condições sociais & \\
\hline 10 & $\begin{array}{l}\text { Promover educação profissional, científica e tecnológica de } \\
\text { forma inclusiva, para reduzir as desigualdades sociais }\end{array}$ & \multirow{2}{*}{$\begin{array}{c}\text { Oferecer EPT a } \\
\text { jovens e adultos, em } \\
\text { situação de } \\
\text { vulnerabilidade social }\end{array}$} & \\
\hline 11 & $\begin{array}{l}\text { Oferecer oportunidades de formação profissional para } \\
\text { jovens e adultos, em situação de vulnerabilidade }\end{array}$ & & \\
\hline
\end{tabular}

Fonte: Elaborado pelo autor (2020).

Os participantes avaliaram a integração da educação básica e educação profissional nos cursos técnicos integrados ao ensino médio oferecidos no IFG campus Itumbiara e 03 avaliaram essa integração como "excelente", 01 "ótima”, 06 "bom", 11 "regular" e 04 "ruim". O ranking médio obtido para essa avaliação foi " 2,52 ", ou seja, os docentes consideram "regular". Os participantes classificaram a oferta de formação continuada sobre a temática "Educação Profissional e Tecnológica" para os docentes do IFG campus Itumbiara, da seguinte forma: 01 "suficiente", 10 "regular", 10 "insuficiente", 04 "escassa". O ranking médio obtido para essa classificação foi "2,32", ou seja, os docentes consideram "insuficiente".

Ainda, sobre a percepção da EPT nos institutos federais, os docentes responderam a seguinte pergunta: "O professor da carreira EBTT tem que atuar em várias modalidades de educação profissional, de cursos de qualificação profissional até a pós-graduação. Como você classifica essa realidade?", e 02 participantes responderam "muito fácil", 01 "fácil", 06 "neutro", 14 "difícil" e 02 "muito difícil". O ranking médio obtido para essa classificação foi "2,48", ou seja, os docentes consideram "difícil". Quanto à atuação, tendo em vista os eixos: ensino, pesquisa e extensão, 11 participantes desenvolvem atividades de ensino e projetos de pesquisa, 03 desenvolvem atividades de ensino e projetos de extensão, 05 atuam nos três eixos e 06 realizam somente atividades em sala de aula.

Estes resultados motivaram e subsidiaram o desenvolvimento de um Guia Docente (Figura 2), em um ambiente virtual de aprendizagem (Moodle), contendo orientações acadêmicas necessárias para o exercício da docência no Instituto Federal de Goiás - campus Itumbiara. O Guia Docente foi disponibilizado inicialmente aos participantes da pesquisa para ajustes e melhorias, e posteriormente aos demais professores do Instituto Federal de Goiás - 
campus Itumbiara, no link: https://moodle.ifg.edu.br/course/index.php?categoryid=167. Ele pode ser acessado por visitantes, com a senha: acessaroguiaifg.

Este produto educacional foi idealizado como uma alternativa para melhorar o acesso e compartilhamentos de informações acadêmicas, bem como, para divulgar orientações sobre a Educação Profissional e Tecnológica, os Institutos Federais, a integração do ensino médio ao técnico.

Figura 2 - Imagens do Produto Educacional "Guia Docente" no aplicativo Moodle Mobile

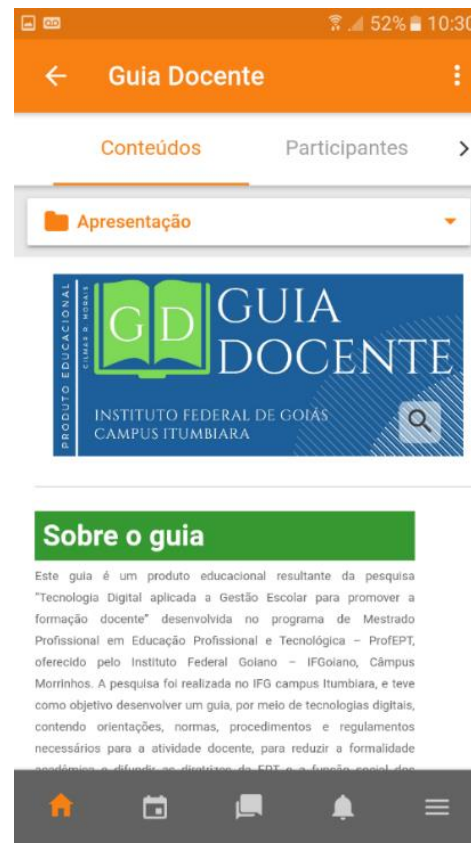

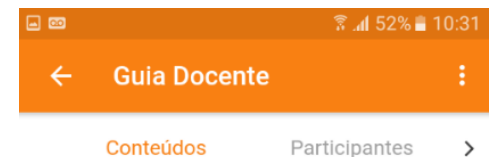

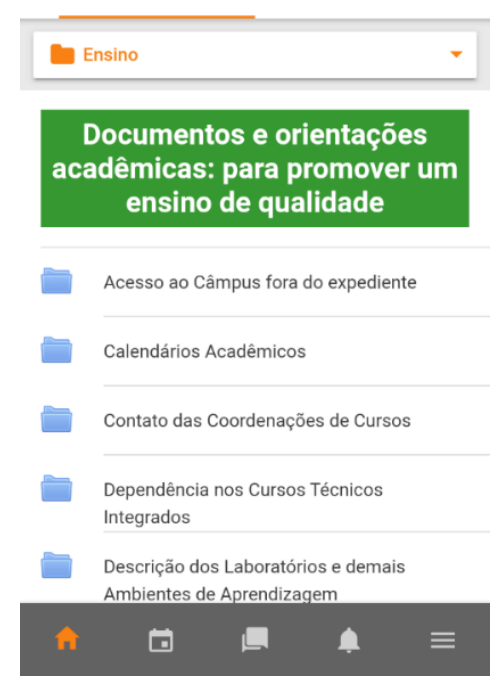

Fonte: Elaborado pelo autor (2020).

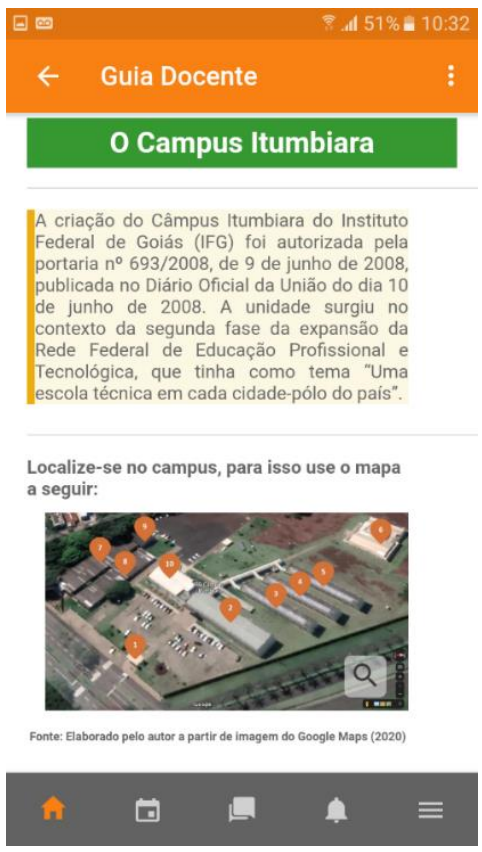

\section{Conclusões}

O perfil dos docentes que atuam no ensino médio integrado no IFG campus Itumbiara, é constituído, em sua maioria, por professores doutores e mestres, oriundos de universidades federais e estaduais, ou seja, possuem uma formação predominantemente acadêmica, e não profissional. Por já serem mestres e doutores, ações como o ProfEPT não atraem estes professores. Nenhum professor participante da pesquisa cursou graduação em Institutos Federais, CEFET ou Escolas Técnicas.

Como dito anteriormente, a maioria dos cursos de mestrado e doutorado formam professores com foco na pesquisa, sem formação pedagógica, e somente a experiência, sem a necessidade da referida formação pedagógica, seria insuficiente para ser um docente da EPT. Ainda, a maioria dos professores participantes da pesquisa são imigrantes digitais, não possuem experiência como gestor e nem como professor de ensino profissionalizante. Alguns nem mesmo possuem experiência no mundo do trabalho, ou seja, não exerceram a sua profissão antes de se tornarem docentes.

Em relação à percepção dos docentes sobre o processo de compartilhamento e acesso à informação, pode-se afirmar que apesar dos participantes considerarem fácil o acesso à documentos, orientações, normas, procedimentos e regulamentos é preciso melhorar a divulgação de informações setoriais e a estrutura do site do IFG. O resultado inconclusivo quanto à formalidade dos procedimentos acadêmicos demonstra uma necessidade de melhorias nos processos de gestão. 
Os docentes utilizam frequentemente o e-mail institucional, sendo este um importante canal de comunicação e informação, por outro lado, observa-se que alguns professores não utilizam o site institucional ou acessam com baixa frequência. Talvez isso ocorra, como já diagnosticado anteriormente, pela dificuldade em acessar informações no site. Quanto à utilização dos sistemas de informação, o resultado foi inconclusivo já que não se pode afirmar se há ou não dificuldade em utilizá-los. Essa incerteza demonstra uma necessidade de melhorias, que podem ser obtidas por meio de treinamento, capacitação ou material educativo oferecido aos professores.

Os docentes, em ampla maioria, não utilizam o Ambiente Virtual de Aprendizagem, muito menos a sua versão mobile, esse resultado provoca algumas reflexões: os professores não utilizam o AVA porque não foram capacitados? Não utilizam porque não sabem utilizá-lo pedagogicamente? Além da necessidade de formação para utilização dos sistemas informacionais, fica evidente também a necessidade de formação destes professores para utilizarem o AVA no ensino médio integrado.

A maioria dos professores não receberam formação inicial e/ou continuada para atuar na EPT, e o seu conhecimento se baseia nos estudos realizados durante a sua preparação para o concurso público, inclusive todos os docentes pertencentes a "ciências exatas" não compreendem a definição de "trabalho como princípio e educativo". Por outro lado, os resultados mostram que os professores compreendem a função social dos Institutos Federais. Quanto à oferta de formação continuada sobre a temática "Educação Profissional e Tecnológica", os participantes consideram insuficiente, por isso, evidencia-se a necessidade de discutir essa temática com os professores e oferecer formação específica.

Os participantes apontam a necessidade de melhorias em relação a integração da educação básica e educação profissional nos cursos técnicos integrados ao ensino médio e consideram difícil a realidade do professor da EBTT por ter que atuar em várias modalidades de educação profissional. A discussão sobre a formação docente para atuar na EPT ocorre desde 2004, e somente agora temos visto alguns IF's ofertarem cursos, licenciaturas e pós-graduação para EPT e assumindo a sua responsabilidade para a formação destes professores. Se a educação profissional se baseia no trabalho como princípio educativo, de fato é necessário formar o professor da EPT em uma base solidificada pela pedagogia do trabalho.

As políticas que foram apontadas nas reflexões teóricas, apesar de fundamentais são insuficientes. Para mudar este cenário, a adoção de tecnologias digitais pela gestão escolar em processos formativos pode contribuir para difundir saberes necessários ao trabalho docente, promover a gestão participativa e a oferta de uma educação profissional de qualidade. No estudo aqui empreendido, o uso de tecnologia possibilitou mobilidade, portabilidade e atemporalidade no compartilhamento e acesso à informações institucionais. Espera-se que este exemplo de aplicação de tecnologia, por parte da gestão escolar, possa ser replicado e aperfeiçoado em outras instituições de ensino.

\section{Referências}

ALMEIDA, A. R.; BOTELHO, D. Construção de questionários. In: BOTELHO, D.; ZOUAIN, D. M. (Orgs.) Pesquisa quantitativa em administração. São Paulo: Atlas, 2009.

ALMEIDA, M. E. B. Tecnologias e gestão do conhecimento na escola In: VIEIRA, A. T.; ALMEIDA, M. E. B.; ALONSO, M. (org.). Gestão educacional e tecnologia. São Paulo: Avercamp, 2003. 
ARXER, E.; INFORSATO, E. C. O Gestor Escolar e as Tecnologias Digitais de Informação e Comunicação (TDIC). CIET: EnPED, [S.1.], maio 2018. ISSN 2316-8722. Disponível em: http://cietenped.ufscar.br/submissao/index.php/2018/article/view/689. Acesso em: 12 mar. 2020.

BARBETTA, P. A. Estatística aplicada às Ciências Sociais / Pedro Alberto Barbetta. 8. ed. rev. Florianópolis: Ed. da UFSC, 2012.

BARDIN, L. Análise de conteúdo. São Paulo: Edições 70, 2016.

BAPTAGLIN, L. Educação Profissional e Tecnológica: O Estado da Arte da Aprendizagem da Docência nos Cursos Técnicos de Ensino Médio Integrado. In: ASSOCIAÇÃO NACIONAL DE PÓS-GRADUAÇÃO E PESQUISA EM EDUCAÇÃO SUL, 10., 2014, Anais [...], Florianópolis: UDESC, 2014. p.1-19. Disponível em:

http://xanpedsul.faed.udesc.br/arq_pdf/206-0.pdf. Acesso em: 22 fev. 2019.

BRASIL. Ministério da Educação. Secretaria de Educação Profissional e Tecnológica. Um novo modelo de educação profissional e tecnológica: Concepção e Diretrizes. Brasília, DF, 2010. Disponível em:

http://portal.mec.gov.br/index.php?option=com_docman\&view=download\&alias=6691-ifconcepcaoediretrizes\&category_slug=setembro-2010-pdf\&Itemid=30192. Acesso em: 11 mar. 2020.

BRASIL. Ministério da Educação. Secretaria de Educação Profissional e Tecnológica.

Educação Profissional Técnica de Nível Médio Integrada ao Ensino Médio: Documento Base. Brasília, DF, 2007. Disponível em:

http://portal.mec.gov.br/setec/arquivos/pdf/documento_base.pdf. Acesso em: 11 mar. 2020.

BRASIL. Lei ${ }^{\circ} 11.741$ de 16 de julho de 2008. Altera dispositivos da Lei no 9.394, de 20 de dezembro de 1996, que estabelece as diretrizes e bases da educação nacional, para redimensionar, institucionalizar e integrar as ações da educação profissional técnica de nível médio, da educação de jovens e adultos e da educação profissional e tecnológica. Diário Oficial da União, Brasília, DF, 17 jul. 2008a. Disponível em: http://www.planalto.gov.br/ccivil_03/_Ato2007-2010/2008/Lei/L11741.htm. Acesso em: 11 mar. 2020.

BRASIL. Lei n ${ }^{0} 11.892$ de 29 de dezembro de 2008. Institui a Rede Federal de Educação Profissional, Científica e Tecnológica, cria os Institutos Federais de Educação, Ciência e Tecnologia, e dá outras providências. Diário Oficial da União, Brasília, DF, 30 dez. 2008b. Disponível em: http://www.planalto.gov.br/ccivil_03/_Ato2007-2010/2008/Lei/L11892.htm. Acesso em: 11 mar. 2020.

BRASIL. Ministério da Saúde. Conselho Nacional de Saúde. Resolução no 466 de 12 de dezembro de 2012. Aprova diretrizes e normas regulamentadoras de pesquisas envolvendo seres humanos. Diário Oficial da União, Brasília, DF, 13 jun. 2013.

CASTELlS, M. A sociedade em rede. São Paulo: Paz e Terra, 1999.

CIAVATTA, M. A formação integrada: a escola e o trabalho como lugares de memória e identidade. Revista Trabalho Necessário, Rio de Janeiro, ano 3, v. 3, 2005. Disponível em: https://periodicos.uff.br/trabalhonecessario/article/view/6122. Acesso em: 12 mar. 2020. 
COSTA, M. A. Políticas de formação de professores para a educação profissional e tecnológica: cenários contemporâneos. 2012. Tese (Doutorado em Educação) - Programa de pós-graduação em Educação, Universidade Federal de Uberlândia, Uberlândia, 2012.

CRUZ, T. L. L. Formação Docente Normativa por meio da Wiki. 2016. 182 f. Dissertação (Mestrado em Ensino de Ciências Humanas, Sociais e da Natureza) - Programa de PósGraduação em Ensino de Ciências Humanas, Sociais e da Natureza, Universidade Tecnológica Federal do Paraná, Londrina, 2016.

FRIGOTTO, G. A gênese do Decreto $n^{\circ}$ 5.154/2004: um debate no contexto controverso da democracia restrita. In: FRIGOTTO, G.; CIAVATTA M.; RAMOS, M. Ensino Médio Integrado: concepção e contradições. 3.Ed. São Paulo: Cortez, 2012.

GIL, A. C. Como elaborar projetos de pesquisa. 5. ed. São Paulo: Atlas, 2010.

GOMES, L. F. et al. Gestão Educacional e Tecnologia: a utilização das TDICS no quadro administrativo e pedagógico. In: REUNIÃO ANUAL DA SOCIEDADE BRASILEIRA PARA O PROGRESSO DA CIÊNCIA, 69., 2017, Belo Horizonte. Resumos [...]. Belo Horizonte: Sociedade Brasileira para o Progresso da Ciência, 2017. p. 1-4. Disponível em: http://www.sbpcnet.org.br/livro/69ra/resumos/resumos/2769_1b52871cb178ecafc4a3fc58e67 e5a5b3.pdf. Acesso em: 28 mar. 2020.

GRAMSCI, A. Os intelectuais e a organização da cultura. 4. ed. Rio de Janeiro: Civilização Brasileira, 1982.

INEP. Formação de Professores para Educação Profissional e Tecnológica: Brasília, 26, 27 e 28 de setembro de 2006. Brasília: Instituto Nacional de Estudos e Pesquisas Educacionais Anísio Teixeira, 2008. 304 p.

KENSKY, V. M. Tecnologias e ensino presencial e a distância. 9. ed. Campinas, SP: Papirus, 2012.

LÉVY, P. Cibercultura. Tradução de Carlos Irineu da Costa. - São Paulo: Editora 34, 1999. $264 \mathrm{p}$.

LIBÂNEO, J. C. Educação escolar: políticas, estrutura e organização. 10. ed. rev. e ampl. São Paulo: Cortez, 2012.

LUCK, H. Dimensões de gestão escolar e suas competências. Heloísa Luck. Curitiba: Editora Positivo, 2009.

MACHADO, L. R. S. Ensino médio e técnico com currículos integrados: propostas de ação didática para uma relação não fantasiosa. In: JAQUELINE MOLL \& Colaboradores. (org.). Educação profissional e tecnológica no Brasil contemporâneo: Desafios, tensões e possibilidades. Porto Alegre, RS: ARTMED, 2010, p. 80-95.

MARCONI, M. A.; LAKATOS, E. M. Fundamentos de metodologia científica. 5. ed. São Paulo: Atlas, 2003.

MARTINS, G.; THEOPHILO, C. Metodologia da investigação científica para ciências sociais aplicadas. São Paulo: Editora Atlas, 2007. 
MENESES FILHO, A.; COSTA, M. A. Formação de professores para a educação profissional e tecnológica: o olhar da legislação (1917-2017). In: COLÓQUIO NACIONAL, 4.;

COLÓQUIO INTERNACIONAL, 1., 2017, Natal. Anais [...]. Natal: IFRN, 2017. p. 1-12.

Disponível em: https://ead.ifrn.edu.br/coloquio/anais/2017/trabalhos/eixo3/E3A3.pdf. Acesso em: 12 mar. 2020.

MOURA, D. H. Educação básica e educação profissional e tecnológica: dualidade histórica e perspectivas de integração. Revista Holos, ano 23, v. 2, 2007.

OLIVEIRA, L. H. Exemplo de cálculo de Ranking Médio para Likert. 2005. Disciplina de Metodologia Científica e Técnicas de Pesquisa em Administração do Mestrado em Administração e Desenvolvimento Organizacional. PPGA CNEC/FACECA: Varginha, 2005. Notas de Aula. Disponível em:

http://www.feis.unesp.br/Home/DTADM/STDARH/EquipedeDesenvolvimento/educacaosau de/documentos/pesquisa/estatistica/media\%20por\%20Likert.doc. Acesso em: 12 mar. 2020.

OLIVEIRA, N. P.; GUEDES-PINTO, A. L. Os professores da EPT e sua formação: dos mestres das oficinas a professores - pesquisadores. In: Maria Clara Kaschny Schneider, Luis Enrique Aguilar (orgs.). Trajetórias de Educação Profissional e Tecnológica. Florianópolis, SC. 2013.

PARO, V. H. A educação, a política e a administração: reflexões sobre a prática do diretor de escola. Educação e Pesquisa, São Paulo, v. 36, n. 3, p. 763-778, set./dez. 2010.

RAMOS, M. Concepção do ensino médio integrado. 2007. In: SEMINÁRIO SOBRE ENSINO MÉDIO. 2007, Rio Grande do Norte. [Anais]. Rio Grande do Norte: Secretaria de Educação do Estado do Rio Grande do Norte, 2007.

RODRIGUES, J. A educação politécnica no Brasil. Niterói: EdUFF, 1998.

SEVERINO, A. J. Metodologia do trabalho científico. 23. Ed. rev. e atual. - São Paulo: Cortez, 2007.

SOUZA, M. A. R. et al. A nova lógica do trabalho dos (as) bibliotecários (as) face às novas tecnologias. 2017. In: MARIA LÍCIA DOS SANTOS [ t al.], (org.). Educação, inclusão e o mundo do trabalho: percalços, desafios e possibilidades. Goiânia. Ed. da PUC Goiás, 2017.

SOUZA, J. C. M.; MACHADO, M. M. História da formação técnica agrícola no Instituto Federal Goiano. 2017. In: MARIA LÍCIA DOS SANTOS [et al.], (org.). Políticas e práticas da educação profissional no IFGOIANO. Goiânia: Ed. da PUC Goiás, 2017.

STRYHALSKI, P. M.; GESSER, V. Formação de Professores da Educação Profissional e Tecnológica: caracterização e dilemas. Boletim Técnico do Senac, Rio de Janeiro, v. 43, n. 2, p. 84-101, maio/ago. 2017.

TRIOLA, M. F. Introdução à Estatística. 7a. Ed. Rio de Janeiro: LTC, 1999.

Recebido em abril de 2020.

Aprovado em novembro de 2020. 
Revista de Educação, Ciência e Tecnologia 